Article

\title{
Problem-Focused Coping Strategies, Workplace Bullying, and Sustainability of HEIs
}

\author{
Amina Muazzam ${ }^{1}$, Ambreen Anjum ${ }^{2}$ and Anna Visvizi ${ }^{3,4, *(\mathbb{C})}$ \\ 1 Department of Applied Psychology, Lahore College for Women University, Lahore 54000, Pakistan; \\ aminamuazzam3@gmail.com \\ 2 Department of Applied Psychology, The Islamia University of Bahawalpur, Bahawalpur 54500, Pakistan; \\ aambreenaanjum@gmail.com \\ 3 Effat College of Business, Effat University, Jeddah 21478, Saudi Arabia \\ 4 Institute of International Studies, SGH Warsaw School of Economics, Al. Niepodległości 162, \\ 02-554 Warsaw, Poland \\ * Correspondence: avisvizi@gmail.com
}

Received: 22 November 2020; Accepted: 15 December 2020; Published: 17 December 2020

\begin{abstract}
Amid the strain related to the necessity of distance learning and related organizational adjustments in higher education institutions (HEIs), this paper re-examines the problem-focused coping strategy and its efficiency in addressing work-related strain. A case for the centrality of a problem-focused coping strategy in maintaining sustainability and resilience of HEIs is made. To this end, the spotlight is directed at workplace bullying in HEIs, which-due to its implications for absenteeism, turnover, and productivity-represents one of the most challenging issues in talent management in HEIs. What is termed here "hidden cost of workplace bullying" constitutes a direct challenge for HEIs sustainability and resilience. The discussion and the findings elaborated in this paper are based on a survey $(n=400)$ conducted across HEIs in Pakistan. It is argued that the findings are generalizable, which makes this paper an important addition to the literature on sustainability and resilience in HEIs.
\end{abstract}

Keywords: talent management; HEI sustainability; bullying; coping strategies; problem-focused coping strategies; managerial implications; the hidden cost of workplace bullying

\section{Introduction}

Higher education institutions (HEIs) worldwide are in the process of transition. They need to adapt to the twin-challenge of the changing political and economic environment in which they operate [1,2] and to the evolving demands, expectations, and capacities of the student body [3]. This twin-challenge means that HEIs worldwide struggle with acquiring finance and transforming their organizational structure and their business model, while at the same time seeking to develop a curriculum that meets the demands and expectations of both the student body and the market. Talent management in this context is not considered a priority. Moreover, more frequently than not, the bulk share of the burden of this multi-scalar transition the HEIs undergo is moved on the shoulders of the faculty [4]. As argued elsewhere, the faculty-for the sake of keeping their promotion options open-is expected to and agrees to engage in additional non-paid "service" activities. As a result, the workload the faculty already has may even double [2]. The COVID-19 pandemic, and the necessity to switch to online distance learning nearly overnight, created an additional source of strain for the faculty as well as for the HEI administration $[5,6]$. The situation of a continued escalation of challenges and burden that the faculty and the administration are exposed to frequently exacerbates pre-existing problems pertinent to the group dynamics, collaboration, equality, fairness, and bullying in a given 
HEI. Research dealing with these issues is still nascent [7]. By focusing on bullying in HEIs, this paper inserts itself in this debate to argue that, especially today, an effective problem-focused coping strategy might be the best way of navigating challenges and issues, of which bullying is but one representation.

The debate on bullying in academia is not new, and yet regrettably the problem persists, and relating research maintains its relevance [8-14]. Diverse forms of bullying exist. The thrust of the phenomenon lies in "the infliction of various forms of abuse (e.g., verbal, emotional, psychological) against a colleague or subordinate by one or more other members of a workplace" [8]. Details about which forms of action bullying can take are redundant at this point. Clearly, several detailed accounts of bullying and its forms exist in the literature $[8,10,12,13]$. The case that this paper seeks to make is that there is a direct correlation between the scale and scope of bullying in HEIs, the ways of coping with bullying and its implications, and the sustainability of HEIs. In other words, considering that bullying in HEIs results in increased absenteeism, increased turnover intention, and decreased productivity, it represents one of the most salient challenges HEIs face today. Its gravity is exacerbated by the fact that workplace bullying in HEIs is underreported.

Given that sustainability and resilience of HEIs, and so quality education [15], are the key goals all societies strive for, this paper re-examines the problem-focused coping strategy in connection to workplace bullying in HEIs. Drawing from the findings of a survey conducted among 400 respondents, faculty members in HEIs in Pakistan, a positive relationship between a problem-focused coping strategy and the degree of individual strain and turnover intention is evidenced. It is argued that the findings elaborated in this paper are generalizable, at least as regards the recommendations and suggestions for HEI administration, which makes this paper an important addition to the literature on talent management and sustainability. The argument in this paper is structured as follows. The following section sheds light on the debate on coping strategies, bullying, and strain in HEIs and links them to the issue of organizational performance of HEIs, including questions of sustainability and resilience. Section 3 elaborates on the methods and methodology applied for this study, including detailed insights into the specific scales applied for the examination and the outcomes of the examination themselves. Discussion and conclusions follow.

\section{Bullying, Problem-Focused Coping Strategy, and Sustainability in HEI}

The discussion on diverse styles of coping strategies and their efficiency in navigating specific situations of stress in an individual's private and professional lives have been thoroughly discussed in the literature [15-20]. In a similar manner, the discussion on bullying in the workplace maintains its momentum [8-14,21-23]. In this context, bullying in HEIs establishes itself as an important and self-standing challenge [24-26]. Bullying in HEIs is a multi-scalar problem [8-10] that affects an individual's well-being and takes such forms as anxiety, insomnia, indigestion, lack of appetite, and others. It also affects an individual's family and family life because the stress and strain are "imported" into the household [27]. Finally, it has an adverse impact on an individual's performance at work. It manifests itself through absenteeism, decreased productivity driven by dwindling motivation, intention to leave, and others [28,29]. As a result, the overall performance of a given HEI falls, and an avalanche of adverse implications follows [30-36]. In the extant research on strategies aimed at coping with stressful work-related situations, the value of problem-focused strategies was frequently stressed [37]. The essence of problem-focused coping strategies rests in a conscious attempt by the victim to resolve the problem by confronting those who are responsible for the situation of strain. This may include direct and instrumentalized forms of action.

Relatively little has been written so far on the correlation between bullying-related strain and efficient coping strategies [38-40]. Even less, however, has been written about the efficient ways of navigating bullying-related strain and implications of bullying in the context of HEIs [41,42]. It remains yet to be determined whether it is valid to consider the context of an HEI on the same par with any other business organization and whether, accordingly, comparisons with and experiences gained in the business sector, especially as regards bullying, can be applied in HEIs $[43,44]$. In several respects, HEIs, 
always on average because exceptions exist, do not stand the comparisons and standards applicable in the business sector [45] and, for instance, are considered as the late adopters of certain organizational, human resources (HR), and leadership solutions [35]. In addition, as research suggests [45,46], there is a certain qualitative specificity to the HEI environments, which may not be applicable to a regular business setting. The key factors that are at play here include the individual personality traits of the faculty that led them to pursue research and teaching, the usually non-profit orientation, the increasingly sensitive and unresolved issue of student seen as the customer, frequently subjective, open-ended, and grossly unfair promotion requirements, and many more. As outlined in the introduction, the case that this paper seeks to make is that there is a direct correlation between the scale and scope of bullying in HEIs, the ways of coping with bullying and its implications, and the sustainability of HEIs. In this view, it is mandatory to examine the intersection of bullying in HEIs and the effectiveness of coping strategies with a view to proposing a few recommendations for the faculty and the administration, including the deans and the human resource management department. This paper does that by evidencing that a problem-focused coping strategy is the most efficient in view of addressing some of the implications of workplace bullying in HEIs. Accordingly, the question is how to exploit this finding and apply it in the context of HEIs worldwide.

\section{Methodology, Methods, and Materials}

The objective of this section is to provide evidence that a positive direct correlation exists between a problem-focused coping strategy and bullying and bullying-related strain in HEIs. The discussion builds on the assumption that bullying-related strain generates a variety of physical and emotional implications for the victims of bullying, which leads to diverse, prolonged, and frequently hidden costs and related losses in productivity in HEIs. By evidencing the said positive correlation, a case is made that, with regards to bullying in HEIs, problem-focused coping strategies represent the most efficient way of dealing with bullying and bullying-related strain. Therefore, a positive correlation exists between problem-focused coping strategies and the sustainability of HEIs. The argument evidencing that draws from the outcomes of a survey $(n=400)$ conducted across HEIs in Pakistan.

\subsection{About the Survey}

For the sake of this research, a survey was conducted. The sample consisted of 400 faculty members $($ men $=200$, women $=200)$ recruited from 12 public universities in Pakistan. The age range of the sample was 24 to 60 years $(M=33.85, S D=8.0)$. A purposive sampling technique was used to collect the sample. The demographic information forms, the Workplace Bullying Scale (WBS), the Workplace Bullying Strain Inventory (WBSI), the Brief Cope Inventory Scale (BCIS), and the Turnover Intention Scale (TIS) questionnaires were individually administered to and completed by all study participants. Each scale was accompanied by a set of written guidelines explaining how the questionnaire should be responded to. All questionnaires were collected personally. The present study was conducted in a manner that respects the dignity, right, and welfare of all the participants of the research. Participants were informed that all the information provided by them would be kept confidential. They were also informed that they could withdraw from the study at any time. The data collected were analyzed using the Statistical Package for the Social Sciences (SPSS) version 20.0 and the Analysis of Moment Structures (AMOS) version 22.0. To assess the internal consistency of the scales, reliability analyses were run, and Cronbach's alphas of all scales were obtained. Regression analyses were employed to identify the role of the independent variable (workplace bullying) on dependent variables (workplace bullying strain) and turnover. The mediation role of problem-focused coping strategies between workplace bullying and bullying strains and turnover was investigated using structural equation modeling (SEM) through AMOS. 


\subsection{The Sample}

There is no statistically systematic record about the faculty in Pakistani HEIs, which could be accessed and adopted as the target population. Furthermore, workplace bullying is a culturally and socially inhibited issue and thus its scale tends to be underreported [47,48]. For these two reasons, it was not acceptable to employ any method of probability sampling strategy. Accordingly, following a cross-sectional design, the purposive sampling approach was employed. A total of 521 faculty members from 12 HEIs in Pakistan were invited to respond to the survey. Of these potential participants, 400 respondents $(\mathrm{men}=200$, women $=200)$ completed the questionnaires. This sets the response rate at $76 \%$. The age range of the survey participants was $24-60$ years $(\mathrm{M}=33.55, \mathrm{SD}=8.0)$. The baseline of academic qualification of the sample was sixteen years of education with a minimum of one year of teaching experience. Non-teaching staff was not included in the present study.

\subsection{The Scales (Measures)}

For the sake of the examination in this study, the following scales were employed: the Workplace Bullying Scale (WBS) to assess the respondents' exposure to bullying; the Workplace Bullying Strain Inventory (WBSI) to assess the strain caused by bullying; the Brief Cope Inventory Scale (BCIS) to assess the respondents' preferred strategies to cope with stressful situations; and the Turnover Intention Scale (TIS-6) to assess the respondent's intention to leave the organization in near future as a result of bullying. The following paragraphs offer an insight into these scales and how they were applied in this study.

The Workplace Bullying Scale (WBS) [49] was used to assess the participants' exposure to bullying. Participants were asked to point out how often over the past six months they had been exposed to negative behaviors associated with bullying; a list of behaviors was listed. This scale consisted of 21 items. All items in the scale were written in a behavioral form. Not a single item of the WBS used the word "bullying". The scale consisted of two subscales. The first subscale, consisting of 10 items, focused on work-related bullying, e.g., withholding necessary information affecting the respondent's professional progress and setting unrealistic goals and deadlines. The second subscale, comprised of 11 items and examined person-related bullying, e.g., spreading rumors, social exclusion, and others. The Cronbach's alphas acquired in the present study are $\alpha=0.77$ and 0.87 for work-related bullying and person-related forms of bullying, respectively, and 0.94 for the total bullying scale. The scale was scored on a 5-point Likert rating scale, where "Never" was scored as 1 and "Daily" as 5.

The Workplace Bullying Strain Inventory (WBSI) [48] was used to assess the bullying strain. The use of the WBSI derived from the assumption that strain results from bullying experience and that it manifests itself in several areas/domains related to job/work, psychology, interpersonal relations/problems, physical, and behavioral issues/problems. The WBSI consisted of 33 items. The scale was scored on a 5-point Likert rating scale where "Never" was scored as 1 and "Always" as 5. The WBSI consisted of 5 subscales. There were 6 items for job strain, 7 items for the dimension of psychological complaints, 6 items for physical complaints, 7 items for interpersonal complaints, and 6 items for the dimension of behavioral complaints. Respondents' higher scores on WBSI were indicative of greater strain in specific areas. The Cronbach's alphas of the five subscales of the WBSI acquired in the present study are $\alpha=0.89,0.87,0.89,0.85,0.86$ for the psychological strain subscale, interpersonal strain subscale, physical strain subscale, job-related strain subscale, and behavioral strain subscale, respectively, and 0.94 for the total WBSI scale. Sample items are "I feel a lack of interest in my office work", "These days I feel depressed due to the problems related to my job", and "I have trouble falling asleep and sleeping well".

To examine how the survey respondents cope with bullying-related strain, the Brief Cope Inventory Scale (BCIS) [50] was used. This scale enables assessing the respondents' preference to apply certain coping strategies over others when facing a stressful situation. While the original scale consists of 28 items, for the purpose of this study, only a 10-items-subscale of problem-focused strategies was used. The sample items of that subscale included: "I've been taking action to try to make the situation 
better" and "I've been trying to get advice or help from other people about what to do". This scale is scored on a four-point rating scale: with responses pertaining 1 "Usually don't do" to 4 "Do this a lot". The Cronbach's alpha for the problem-focused coping scale for this study was 0.97 . The higher scores on the BCIS indicated a greater preference and tendency to use these coping strategies.

Finally, the Turnover Intention Scale (TIS-6) [51] was applied to assess the respondents' intention to leave the HEI organization in near future. The original version of this TIS- 6 consists of 14 items [43], but its shorter version is also available [52] and consists of 6 items. The items included in the TIS-6 applied in this study were as follows: "How often have you considered leaving your job?" and "How likely are you to accept another job at the same compensation level should it be offered to you?" The Cronbach's alpha for the Turnover Intention Scale on present data was 0.82 . The higher the score on the TIS- 6 scale, the greater the intention to leave the institution.

\subsection{The Results}

The following seven tables, i.e., Tables 1-7, offer an insight into the results of the detailed analysis of the responses to the survey. Each table dwells on a specific issue, an item comprising the research model applied in this study. Table 7 serves as the most important table, perhaps, as it confirms the positive correlations between a problem-focused coping strategy, the faculty's degree of bullying-related strain, and intention to leave the organization. Details are provided below.

Table 1 offers an insight into the descriptive statistics, Cronbach's alphas, and inter-correlations of the study variables. With the goodness of fit at 0.99 , the comparative fit index at 0.99 , goodness of index at 0.1 , the root mean square of residual at 0.02 , and $x^{2} / \mathrm{df}$ ratio at 2.76 showing that the proposed model provided a good fit to the data. Forty-two percent of teachers reported experience of workplace bullying in their respective institutions. Findings indicate that bullying positively and significantly predicted bullying strains and turnover intentions, and this relationship was mediated by problem-focused coping strategies. Table 1 shows that all scales possess excellent reliability and support the use of these scales in the present study [53].

Table 1. Descriptive statistics, Cronbach's alphas, and inter-correlations of the study variables $(\mathrm{N}=400)$.

\begin{tabular}{cccccc}
\hline Scales & $\mathbf{1}$ & $\mathbf{2}$ & $\mathbf{3}$ & $\mathbf{4}$ & $\mathbf{A}$ \\
\hline 1-Work-bs & - & $0.54^{* *}$ & $0.34^{* *}$ & $0.20^{* *}$ & 0.90 \\
2-Bul-si & - & - & $0.22^{* *}$ & $0.18^{* *}$ & 0.83 \\
3-Prob-foc & - & - & - & $0.13^{* *}$ & 0.88 \\
4-Turnover & & & & & 0.82 \\
M & 53.84 & 92.14 & 23.72 & 22.58 & \\
SD & 10.63 & 25.75 & 10.26 & 3.27 & \\
\hline
\end{tabular}

${ }^{* *} p<0.01$. Note: Work-bs = Workplace Bullying Scale, Bul-si = Workplace Bullying Strain Inventory, Prob-foc $=$ problem-focused coping.

Table 2 demonstrates that $42 \%$ of the participants reported bullying exposure, while $58 \%$ of the participants were never exposed to workplace-bullying. Women were subjected to bullying more frequently $(66 \%)$ as compared to male faculty members.

Table 2. Percentage of higher education teachers according to bullying exposure $(\mathrm{N}=400)$.

\begin{tabular}{cccc}
\hline \multirow{2}{*}{ Bullying Exposure } & $\begin{array}{c}\text { Men (N=200) } \\
\mathbf{n ~ ( \% )}\end{array}$ & $\begin{array}{c}\text { Women }(\mathbf{N}=\mathbf{2 0 0 )} \\
\mathbf{n}(\mathbf{\%})\end{array}$ & $\begin{array}{c}\text { Total (N = 400) } \\
\mathbf{n ~ ( \% )}\end{array}$ \\
\hline Bullied & $36(18)$ & $132(66)$ & $168(42)$ \\
Non-bullied & $164(82)$ & $68(34)$ & $232(58)$ \\
\hline
\end{tabular}

Table 3 indicates that workplace bullying is a significant positive predictor of coping strategies as it explained $12 \%$ of the variance in coping strategies. Workplace bullying is a significant positive 
predictor of bullying strain $(B=0.54, p<0.001)$ as well as it explained $30 \%$ of the variance in workplace bullying strain. Table 3 also shows that the predictability of turnover is the result of exposure to workplace bullying. Results show that workplace bullying is a significant positive predictor of turnover $(ß=0.20, p<0.001)$; it accounted for $4 \%$ of the variance in turnover intention.

Table 3. Linear regression for predicting use of coping strategies, strains, and turnover from workplace bullying exposure $(\mathrm{N}=400)$.

\begin{tabular}{|c|c|c|c|c|c|c|c|c|c|}
\hline \multirow[t]{2}{*}{ Variables } & \multicolumn{3}{|c|}{ Coping } & \multicolumn{3}{|c|}{ Strains } & \multicolumn{3}{|c|}{ Turnover } \\
\hline & B & SEB & $\beta$ & B & SEB & B & B & SEB & $B$ \\
\hline \multirow{2}{*}{$\begin{array}{c}\text { Workplace } 0.33 \\
\text { Bullying } \\
\mathrm{R}^{2}\end{array}$} & & 0.04 & $0.34^{* * *}$ & 1.31 & 0.10 & $0.54^{* * *}$ & 0.06 & 0.01 & $0.20^{* * *}$ \\
\hline & & 0.12 & & & 0.30 & & & 0.04 & \\
\hline F & & 54.58 & & & 21.63 & & & 167.05 & \\
\hline
\end{tabular}

$* * * p<0.001$. Note: SEB $=$ Standard Error of the Un Standardized Beta.

Table 4 offers an insight into person-related and work-related bullying subscales that were examined through the stepwise regression analysis. Accordingly, Table 4 shows that $18 \%$ of the variance in bullying strain is accounted for by work-related exposure to bullying alone. At the same time, work-related and person-related bullying collectively account for $30 \%$ of the variance in bullying strains. $\mathrm{F}=92.71,83.10, p<0.001$ supported the model. Thus, both types of bullying were found to serve as significant predictors of bullying strain.

Table 4. Stepwise regression for predicting bullying strain from the subscales of workplace bullying $(\mathrm{N}=400)$.

\begin{tabular}{cccc}
\hline Model & B & SEB & $\beta$ \\
\hline 1. Constant & 43.8 & 5.15 & $0.43^{* * *}$ \\
\hline Job-related bullying & 1.73 & & \\
\hline $\mathrm{R}^{2}$ & 0.18 & & \\
\hline $\mathrm{F}$ & 92.71 & & \\
\hline 2. Constant & 20.91 & 5.64 \\
\hline Job-related bullying & 1.38 & 0.17 & $0.34^{* * *}$ \\
\hline Person-related bullying & 1.25 & 0.16 & $0.33^{* * *}$ \\
\hline $\mathrm{R}^{2}$ & 0.3 & \\
\hline $\mathrm{F}$ & 83.1 \\
\hline
\end{tabular}

Table 5 demonstrates the results of the stepwise regression analysis of the workplace bullying subscales. On the person-related subscale, bullying appeared as a significant predictor of workplace bullying strains ( $B=0.19, p<0.001$ ), while person-related exposure to bullying explained $3 \%$ of the variance in employees' turnover intention. 
Table 5. Stepwise regression for predicting turnover from the subscales of workplace bullying $(\mathrm{N}=400)$.

\begin{tabular}{cccc}
\hline Model & B & SEB & $\beta$ \\
\hline 1. Constant & 20.21 & 0.62 & \\
\hline Person-related bullying & 0.09 & 0.02 & $0.19^{* * *}$ \\
\hline $\mathrm{R}^{2}$ & 0.03 & \\
\hline $\mathrm{F}$ & 15.36 \\
\hline \multicolumn{5}{c}{ Note: $^{* * *} p<0.001}$.
\end{tabular}

Table 6 offers evidence that the model applied for this study fits the data. The above model is judged to be a good-fit model as $\chi^{2}=2.76$ with a $p$-value $>0.05$; the values of the comparative fit index (CFI), Bollen's incremental fit index (IFI), and goodness of fit index (GFI) are higher than 0.90, and root mean square residual (RMSR) is less than 0.08 [54]. The ratio of $\chi^{2} / \mathrm{df}$ was used as a further goodness-of-fit criterion that is not larger than 5 . Therefore, the model fits the data well [55].

Table 6. Fit indices for the mediation model $(\mathrm{N}=400)$.

\begin{tabular}{ccccccc}
\hline Model & $\chi^{2}$ & df & CFI & IFI & GFI & RMSR \\
\hline & 2.76 & 1 & 0.99 & 0.96 & 0.1 & 0.02 \\
\hline
\end{tabular}

Note: $\chi^{2}=$ chi-square, $\mathrm{df}=$ degree of freedom, $\mathrm{CFI}=$ comparative fit index, IFI = Bollen's incremental fit index, $\mathrm{GFI}=$ goodness of fit index, RMSR $=$ root mean square residual.

Table 7 showcases that the standardized direct effects of workplace bullying are a significant predictor of bullying strain and employees' turnover. According to the findings shown in Table 7, problem-focused coping strategies fully mediate the relationship between bullying exposure, employees' strains ( $(=0.07, p=n . s)$, and their intention of turnover $(B=0.02, p=n . s)$. Accordingly, it can be argued that problem-focused coping strategies can mitigate the effects of bullying on employees' level of strain and their turnover intention.

Table 7. Standardized direct, indirect, and total effects of workplace bullying on bullying strains and turnover intention $(\mathrm{N}=400)$.

\begin{tabular}{cccccccc}
\hline Predictor & Outcome & $\begin{array}{c}\text { Direct } \\
\text { Effect }\end{array}$ & Lower-Upper & $\begin{array}{c}\text { Indirect } \\
\text { Effect }\end{array}$ & Lower-Upper & Total & $p$ \\
\hline Workplace bullying & Strains & 0.52 & $0.45-0.60$ & 0.02 & $-0.01-0.05$ & 0.54 & 0.000 \\
Workplace bullying & Turnover intention & 0.18 & $0.06-0.28$ & 0.02 & $-0.00-0.06$ & 0.20 & 0.000 \\
Workplace bullying & Coping & 0.34 & & & & 0.34 & 0.000 \\
Coping & Strains & 0.07 & & & 0.07 & 0.170 \\
Coping & Turnover & 0.02 & & & 0.02 & 0.342 \\
\hline
\end{tabular}

\subsection{A Few Words on the Limitation of This Study}

There are three key limitations to this study. First, the data were collected through a self-reporting method. This might have exacerbated the already existing problem of the underreporting of workplace bullying $[8,10,30,54]$. The suggestion, therefore, is that future research dealing with the problem examined here is enriched by focus groups and interviews. In this way, more detailed information about the frequency, severity, and consequences of bullying might be collected. Second, the respondents invited to this study were only from public HEIs. Even if, at face value, adding respondents from private HEIs would add to the discussion, a decision was made not to do so at this point. Research suggests that the prevalence of workplace bullying is higher in public HEIs [56]. At the same time, a case can be made that dissimilarity in work environments between public and private HEIs exists. This issue has to be factored into the analysis. This is the subject of our ongoing exploration. Third, the discussion in the paper might have benefitted from additional covariates in the regression analysis, e.g., work-family conflict, the institutional environment where bullying takes place, victims' personality 
type, and his/her personal characteristics, such as age, gender, job rank, and length of experience. The inclusion of these factors would certainly add a more sophisticated twist to the analysis. To remain concise and focused on the purpose of the study, these covariates were not addressed in this study. Notably, these factors not only enhance the occurrence of bullying but may also lessen the coping process. All things considered, these issues shall be addressed in our future research.

\section{Discussing the Survey's Results}

The objective of this paper was to query the relationship between bullying and bullying-related strain in HEIs and the efficiency of problem-focused coping strategies seen as a function of HEIs' sustainability. The key assumption on which the discussion in this paper was built is that workplace bullying in HEIs—due to its implications for absenteeism, turnover, and productivity-represents one of the most challenging issues in talent management in HEIs. It was argued that the diverse, prolonged, and hidden implications of workplace bullying in HEIs, a phenomenon termed here as the "hidden cost of workplace bullying", constitutes a direct challenge for HEI sustainability and resilience. To support these interrelated assumptions, a survey $(n=400)$ was conducted across HEIs in Pakistan. The findings of the analysis performed on the outcomes of the survey are discussed below.

The results of this study confirm the initial assumption that bullying in HEIs is a common practice [57-59]. Indeed, $42 \%$ of the HEI faculty who responded to this survey indicated that they were subjects to work-related bullying (see Table 2). These findings are consistent, but not identical, with the findings presented in the broader literature on the subject [57]. Country-level disparities, institutional specificity, and (organizational) culture are the key factors that determine the emergence and forms of workplace bullying [60-62]. These factors are complemented by such issues as an increased demand for efficiency in HEIs, a tendency for an over-evaluation of the faculty, an incommensurate weight of students' opinions in the overall evaluation of the faculty, frequently subjective and overall unfair rules defining the prospect of promotion, and many others, including the changing global landscape of education [63]. The same factors also play a role vis-à-vis the degree of tolerance for workplace bullying behaviors, and finally vis-à-vis self-reporting of acts of bullying.

To explore the bullying strain, it was assumed that experience of workplace bullying predicts psychological health complaints, physical strain, interpersonal strain, job-related strain, and behavioral strain. Regression analyses performed for the purpose of this study showed that workplace bullying exposure significantly predicted bullying strain. These outcomes are in line with the findings of earlier studies [64-67] that made a clear connection between exposure to bullying in the workplace and propensity for depression, anxiety, low self-esteem, and others. Empirical evidence indicates that bullying impacts all aspects of targets' lives.

Workplace bullying bears significant costs for any organization. The cost can be quantified, but it is rather the qualitative dimension of the cost that, paradoxically, is the costliest for organizations. In the case of HEIs, the loss of talent due to high turnover, or under-exploitation of the talent aboard, is responsible for what we call the "hidden cost of workplace bullying". As argued earlier in this paper, victims of bullying tend to underperform in general, where underperformance may take the form of increased absenteeism, lesser commitment to workplace duties and obligations, the resultant decreased quality and quantity of performance, and many others. Institutional turnover is one of the major possible consequences of bullying [11-13,65-68]. In this study, a simple linear regression analysis was employed to test if workplace bullying may significantly predict the respondents' intention of turnover. The finding shows that the predictor explained $4 \%$ of the variance $(B=0.20, p<0.001)$.

This study also examined the mediating role of problem-focused coping strategies in association with workplace bullying, bullying strain, and turnover intention (see Table 3). It was hypothesized that problem-focused coping strategies will mediate the relationship between workplace bullying and bullying strain and employees' turnover intention. To examine this the classic mediational analysis was applied [69-71]. In order to meet the initial criteria, set by Baron and Kenny [69], significant relationships were established between (i) the independent variable (workplace bullying) and dependent variables 
(strain and turnover); (ii) the independent variable and mediator (problem-focused coping); and (iii) between the mediator variable and the outcome variables (strains and turnover) (see Table 3).

The condition of mediation also requires that the independent variable must have no effect on the outcome variable when the mediator is held constant (full mediation) or should become significantly smaller (partial mediation). To test the mediation analysis the SEM approach was used. Results describe a good fit of the hypothesized model to the data. According to the findings of this study, problem-focused coping strategies mediate the relationship between workplace bullying, bullying strain, and employee turnover. These results echo the finding described earlier in the literature on the subject [72,73]. What is interesting, and the results of this study confirm it, the problem-focused coping strategy proved an effective mediator of workplace-bullying-related strain and the intention of turnover. This is consistent with arguments raised in the literature that stress that active coping strategies, of which problem-focused coping strategies are a part, tend to yield sustainable solutions to problems, in this case, to bullying in HEIs and its diverse implications [73-80].

\section{Conclusions}

The objective of this paper was to query the relationship between bullying and bullying-related strain in HEIs and the efficiency of problem-focused coping strategies seen as a function of HEIs' sustainability. A study based on the responses of 400 individuals, faculty members in HEIs in Pakistan, provided evidence for a positive relation between problem-focused coping strategies and the implications of workplace bullying. Throughout the paper, the negative long-term and frequently hidden implications of workplace bullying on the overall performance of HEIs were stressed. We termed them the "hidden cost of workplace bullying" in HEIs. To this end, we argued that the hidden, frequently unaccounted for, yet very pricy, cost of bullying in HEIs may unfold at three interconnected dimensions, including (i) adverse effects on an individual's well-being, as evidenced by anxiety, insomnia, indigestion, lack of appetite, and others; (ii) adverse effects on an individual's family and family life because of stress and strain that are "imported" into their households; and (iii) an adverse impact on an individual's performance at work, as it manifests itself through absenteeism, decreased productivity driven by dwindling motivation, intention to leave, and others. As it was argued in this paper, the hidden cost of workplace bullying in HEIs is immense, and yet it remains under-explored and under-rated. Against this backdrop, this paper sought to stress that active problem-focused coping strategies represent the most efficient way of navigating the multi-scalar challenge of bullying in HEIs. The promise that the problem-focused coping strategies bear is derived from the fact that the victims are enabled and empowered to confront those who are responsible for the situation of strain, in this case, bullying. This may include direct and instrumentalized forms of action. The remainder of this paper sheds light on what could be done to reify the value of addressing bullying and bullying-related strain in HEIs through problem-focused coping strategies. The following three points, seen merely as an introduction to a conversation, are dedicated to a brief discussion on soft and hard tools of purposeful problem-focused coping strategies that HEIs might promote.

As for hard tools, these would entail legal and paralegal measures the victims of bullying might refer to. However, grievances and lawsuits tend to be inefficient when it comes to workplace bullying in HEIs. Frequently, faculty manuals do not expressly foresee the possibility of reacting to acts of bullying; ad hoc committees that might be established to deal with a complaint tend to be either biased or confined by their own members' fear of the implications of going against a superior. As regards lawsuits, these require time and resources, rare goods in the world of HEIs.

As for soft tools associated with problem-focused coping strategies, there is an urgent need for space for the faculty to socialize and relax at the premises of a given HEIs. There is a need for a faculty space clearly delineated from areas accessible by students and by the administration. The faculty needs to have the possibility to develop soft tools of active response to instances of bullying, caused by the fellow faculty member(s) and by the administration, including the deans. The soft tools of response, serving as necessary enablers of problem-focused coping strategies require friendship, skilled helpers, 
and genuine buffering of groups and individuals. These informal institutions can only develop and thrive if the faculty can build and develop their group identity. Failure by the administration to provide for such a space is a serious hindrance.

What follows is that HEIs need to have clearly written faculty manuals that give the faculty members the possibility of having justice served. This requires that open and confidential channels of communication exist where victims of bullying can seek first instance support. Several institutional solutions to this idea exist, and the actual model that might be developed will be a function of a given institution's culture, resources, and tradition. In this context, however, the role of accreditation bodies, for instance, NEASC or AACSB, should be stressed. Their institutional review process should include the question pertaining to workplace bullying and unfair behavior both toward the faculty, among the faculty, and by the faculty. This means that a 360 counter-bullying strategy may make a difference. This paper sought to contribute to the debate.

Author Contributions: Conceptualization, A.M., A.A., and A.V.; methodology, A.M., A.A., and A.V.; software, A.M. and A.A.; validation and formal analysis, A.M. and A.A.; original draft preparation, A.M., A.A., and A.V. All authors have read and agreed to the published version of the manuscript.

Funding: This research was partially supported by the Lahore College for Women University.

Acknowledgments: We would like to thank Ahmad Faisal Mirza for providing technical support in terms of data collection and arrangement.

Conflicts of Interest: The authors declare no conflict of interest.

\section{References}

1. Visvizi, A.; Lytras, M.D.; Daniela, L. How to Predict the Unpredictable: Technology-Enhanced Learning and Learning Innovations in Higher Education. In The Future of Innovation and Technology in Education: Policies and Practices for Teaching and Learning Excellence; Emerald Publishing: London, UK, 2018; pp. 11-26, ISBN 9781787565562.

2. Visvizi, A.; Lytras, M.D.; Sarirete, A. Emerging Technologies and Higher Education: Management and Administration in Focus. In Management and Administration of Higher Education Institutions at Times of Change; Emerald Publishing: London, UK, 2019; ISBN 9781789736281.

3. Visvizi, A.; Field, M.; Pachocka, M. (Eds.) What is at stake in teaching the EU in times of Brexit? An Introduction. In Teaching the EU: Fostering Knowledge Understanding in the Brexit Age, Bingley; Emerald Publishing: London, UK, 2021.

4. Available online: https://www.purdue.edu/butler/documents/WPS-Special-Issue-Higher-Education-andCOVID-19---2020-Volume-3-Issue-2.pdf (accessed on 10 November 2020).

5. Daniela, L.; Visvizi, A. (Eds.) Distance Learning in Times of Pandemic: Issues, Implications and Best Practice; Routledge: New York, NY, USA, 2020.

6. Sokołowski, M.M. Regulation in the COVID-19 pandemic and post-pandemic times: Day-watchman tackling the novel coronavirus. Transform. Gov. People Process. Policy 2020. [CrossRef]

7. Safieddine, M.; Kassir, R. COVID 19 and the race to publish: An ethical issue. Br. J. Surg. 2020, 10, 158.

8. Faria, J.R.; Mixon, F.G.; Salter, S.P. An economic model of workplace mobbing in academe. Econ. Educ. Rev. 2020, 31, 720-726. [CrossRef]

9. Fahie, D. Blackboard bullies: Workplace bullying in primary schools. Ir. Educ. Stud. 2014, 33, 435-450. [CrossRef]

10. Staub, S. Mobbing in Academia: Case Analysis. Int. J. Sch. Cogn. Psychol. 2015, 2, 1-7. [CrossRef]

11. Prevost, C.; Hunt, E. Bullying and Mobbing in Academe: A Literature Review. Eur. Sci. J. ESJ 2018, 14, 1-15. [CrossRef]

12. Taylor, E.A.; Hardin, R.; Welch, N.; Smith, A.B. Incivility in the workplace: The experiences of female sports management faculty in higher education. J. High. Educ. Manag. 2020, 32, 180-198.

13. Keashly, L. Workplace Bullying, Mobbing and Harassment in Academe: Faculty Experience. In Handbook of Workplace Bullying, Emotional Abuse and Harassment; D'Cruz, P., Nornha, E., Keashly, L., Tye-Williams, S., Eds.; Springer: Singapore, 2019. 
14. Jones, S.R.; Stephens, M.L. Faculty incivility toward graduate students: Voices of two African American women. J. Underrepresent Minority Prog. 2020, 4, 94-100.

15. Anjum, A.; Muazzam, A. Workplace bullying and physical health of teachers working in higher education institutes. J. Post Grad. Med Inst. Peshawar 2019, 33, 227-230.

16. Visvizi, A.; Daniela, L.; Chen, C.-W. Beyond the ICT- and sustainability hypes: A case for quality education. Comput. Hum. Behav. 2020, 107, 106304. [CrossRef]

17. Stahl, G.K.; Caligiuri, P. The Effectiveness of Expatriate Coping Strategies: The Moderating Role of Cultural Distance, Position Level, and Time on the International Assignment. J. Appl. Psychol. 2005, 90, 603-615. [CrossRef] [PubMed]

18. Baker, J.P.; Berenbaum, H. Emotional approach and problem-focused coping: A comparison of potentially adaptive strategies. Cogn. Emot. 2007, 21, 95-118. [CrossRef]

19. Heppner, P.P.; Cook, S.W.; Wright, D.M.; Johnson, W.C. Progress in resolving problems: A problem-focused style of coping. J. Couns. Psychol. 1995, 42, 279-293. [CrossRef]

20. Chao, R.C.-L. Managing Stress and Maintaining Well-Being: Social Support, Problem-Focused Coping, and Avoidant Coping. J. Couns. Dev. 2011, 89, 338-348. [CrossRef]

21. Kaiseler, M.; Polman, R.; Nicholls, A. Mental toughness, stress, stress appraisal, coping and coping effectiveness in sport. Pers. Individ. Differ. 2009, 47, 728-733. [CrossRef]

22. Avey, J.B.; Luthans, F.; Jensen, S.M. Psychological capital: A positive resource for combating employee stress and turnover. Hum. Resour. Manag. 2009, 48, 677-693. [CrossRef]

23. Oyeleye, O.; Hanson, P.; O'Connor, N.; Dunn, D. Relationship of Workplace Incivility, Stress, and Burnout on Nurses' Turnover Intentions and Psychological Empowerment. JONA 2013, 43, 536-542. [CrossRef]

24. Muazzam, A.; Manzoor, F.; Visvizi, A.; Pollock, G.; Nawaz, R. Anjum Measuring the Scale and Scope of Workplace Bullying: An Alternative Workplace Bullying Scale. Sustainability 2019, 11, 4634.

25. Huang, S.; Van Der Veen, R.; Song, Z. The impact of coping strategies on occupational stress and turnover intentions among hotel employees. J. Hosp. Mark. Manag. 2018, 27, 926-945. [CrossRef]

26. Anjum, A.; Muazzam, A.; Manzoor, F.; Visvizi, A.; Nawaz, R. Mediating Bullying and Strain in Higher Education Institutions: The Case of Pakistan. Sustainability 2019, 11, 2244. [CrossRef]

27. Hollis, L.P. Analysis of Faculty Wellness and Workplace Bullying, Online Submission. In Proceedings of the Annual Meeting of the American Educational Research Association (AERA), Toronto, ON, Canada, 6 April 2019.

28. Gloor, J.L. Taking the Liberty of Incivility: Workplace Bullying in Higher Education. Hum. Resour. Dev. Q. 2014, 25, 121-126. [CrossRef]

29. Ahmad, M.; Muazzam, A.; Anjum, A.; Visvizi, A.; Nawaz, R. Linking Work-Family Conflict (WFC) and Talent Management: Insights from a Developing Country. Sustainability 2020, 12, 2861. [CrossRef]

30. Meriläinen, M.; Nissinen, P.; Kõiv, K. Intention to leave among bullied university personnel. Int. J. Educ. Manag. 2019, 33, 1686-1704. [CrossRef]

31. Ramohai, J. Women in senior management positions at South African universities: Their movement in, out and across universities. Gend. Manag. Int. J. 2019, 34, 217-232. [CrossRef]

32. Riolli, L.; Savicki, V. Impact of Fairness, Leadership, and Coping on Strain, Burnout, and Turnover in Organizational Change. Int. J. Stress Manag. 2006, 13, 351-377. [CrossRef]

33. Bridger, R.S.; Day, A.J.; Morton, K. Occupational stress and employee turnover. Appl. Erg. 2013, 56, 1629-1639. [CrossRef]

34. Hassan, S.; Waheed, H.; Aljohani, N.R.; Ali, M.; Ventura, S.; Herrera, F. Virtual learning environment to predict withdrawal by leveraging deep learning. Int. J. Intell. Syst. 2019, 34, 1935-1952. [CrossRef]

35. Visvizi, A.; Lytras, M.D.; Daniela, L. Education, Innovation and the Prospect of Sustainable Growth and Development. In The Future of Innovation and Technology in Education: Policies and Practices for Teaching and Learning Excellence, Emerald Studies in Higher Education, Innovation and Technology; Visvizi, A., Lytras, M.D., Daniela, L., Eds.; Emerald Publishing: Bingley, UK, 2018; pp. 297-305, ISBN 9781787565562. [CrossRef]

36. Alyoubi, A.O.; Al-Hayani, A.; Bardesi, H.J.; Basheri, M.; Lytras, M.D.; Aljohani, N.R. The King Abdulaziz University (KAU) Pandemic Framework: A Methodological Approach to Leverage Social Media for the Sustainable Management of Higher Education in Crisis. Sustainability 2020, 12, 4367. [CrossRef]

37. Herman, J.L.; Tetrick, L.E. Problem-focused versus emotion-focused coping strategies and repatriation adjustment. Hum. Resour. Manag. 2009, 48, 69-88. [CrossRef] 
38. Gillespie, M.W.N.A.; Walsh, M.; Winefield, A.H.; Dua, J.; Stough, C. Occupational stress in universities: Staff perceptions of the causes, consequences and moderators of stress. Work. Stress 2001, 15, 53-72. [CrossRef]

39. Tenenbaum, L.S.; Varjas, K.; Meyers, J.; Parris, L. Coping strategies and perceived effectiveness in fourth through eighth grade victims of bullying. Sch. Psychol. Int. 2011, 32, 263-287. [CrossRef]

40. Coetzee, M.; Van Dyk, J. Workplace Bullying and Turnover Intention: Exploring Work Engagement as a Potential Mediator. Psychol. Rep. 2017, 121, 375-392. [CrossRef]

41. Woodward, D. Work-life balancing strategies used by women managers in British "modern" universities. Equal. Oppor. Int. 2007, 26, 6-17. [CrossRef]

42. Iqbal, A.; Kokash, H. Faculty Perception of Stress and Coping Strategies in a Saudi Private University: An Exploratory Study. Int. Educ. Stud. 2011, 4, 137-149. [CrossRef]

43. Visvizi, A.; Lytras, M.D.; Sarirete, A. By Means of Conclusion: ICT at the Service of Higher Education in a Transforming World. In Management and Administration of Higher Education Institutions at Times of Change; Emerald Publishing: London, UK, 2019; ISBN 9781789736281.

44. Bryde, D.J.; Leighton, D. Improving HEI Productivity and Performance through Project Management. Educ. Manag. Adm. Lead. 2009, 37, 705-721. [CrossRef]

45. Muazzam, A.; Tiwana, S. Impact of Goal setting on Organizational Commitment of Employee. J. Arts Soc. Sci. 2015, 2, 2-15.

46. Einarsen, S.V.; Hoel, H.; Zapf, D.; Cooper, C.L. Bullying and Harassment in the Workplace: Theory, Research and Practice; Routledge: New York, NY, USA, 2018.

47. Anjum, A.; Muazzam, A. The Gendered Nature of Workplace Bullying in the Context of Higher Education. Pakistan J. Psychol. Res. 2018, 33, 493-505.

48. Anjum, A.; Muazzam, A. Workplace Bullying and Turnover Intention among University Teachers. J. Arts Soc. Sci. 2018, 2, 16 .

49. Anjum, A.; Shoukat, A. Workplace Bullying: Prevalence and Risk Groups in a Pakistani Sample. J. Public Adm. Gov. 2013, 3, 226. [CrossRef]

50. Carver, C.S. You want to measure coping but your protocol's too long: Consider the brief COPE. Int. J. Behav. Med. 1997, 4, 92-100. [CrossRef]

51. Roodt, G. Turnover intentions. Unpublished document. Johannesbg. Univ. 2004, 2, 13.

52. Bothma, C.F.; Roodt, G. The validation of the turnover intention scale. J. Hum. Resour. Manag. 2013, 11, 12. [CrossRef]

53. Field, A. Discovering Statistics Using IBM SPSS Statistics; Sage Publications, Ltd.: London, UK, 2017.

54. Bentler, P.M. Comparative fit indexes in structural models. Psychol. Bull. 1990, 107, 238-246. [CrossRef] [PubMed]

55. Kline, R.B. Principles and Practice of Structural Equation Modeling, 3rd ed.; Guilford Press: New York, NY, USA, 2011.

56. Giorgi, G.; Arenas, A.; Leon-Perez, J.M. An Operative Measure of Workplace Bullying: The Negative Acts Questionnaire across Italian Companies. Ind. Health 2011, 49, 686-695. [CrossRef] [PubMed]

57. Hollis, L.P. Bully University? The Cost of Workplace Bullying and Employee Disengagement in American Higher Education. Sage Open 2015, 5, 11. [CrossRef]

58. Hubert, A.B.; Veldhoven, M.V. Risk sectors for undesirable behavior and mobbing. Eur. J. Work Organ. Psychol. 2020, 10, 415-424. [CrossRef]

59. Misawa, M.; Rowland, M.L. Academic Bullying and Incivility in Adult, Higher, Continuing, and Professional Education. Adult Learn. 2014, 26, 3-5. [CrossRef]

60. Giorgi, G.; Leon-Perez, J.M.; Arenas, A. Are Bullying Behaviors Tolerated in Some Cultures? Evidence for a Curvilinear Relationship between Workplace Bullying and Job Satisfaction among Italian Workers. J. Bus. Ethic 2014, 131, 227-237. [CrossRef]

61. Ahmad, S.; Kaleem, A. Zooming in on the workplace bullying and turnover intentions pathway. Pers. Rev. 2019, 49, 425-444. [CrossRef]

62. Keashly, L.; Neuman, J.H. Faculty Experiences with Bullying in Higher Education. Adm. Theory Prax. 2010, 32, 48-70. [CrossRef]

63. Visvizi, A.; Lytras, M.D.; Daniela, L. The Future of Innovation and Technology in Education: A Case for Restoring the Role of the Teacher as a Mentor. In The Future of Innovation and Technology in Education: Policies and Practices for Teaching and Learning Excellence; Emerald Publishing: London, UK, 2018; ISBN 9781787565562. 
64. Mikkelsen, E.G.; Einarsen, S. Basic assumptions and post-traumatic stress among victims of workplace bullying. Eur. J. Work Organ. Psychol. 2002, 11, 87-111. [CrossRef]

65. Quine, L. Workplace Bullying in Nurses. J. Health Psychol. 2001, 6, 73-84. [CrossRef] [PubMed]

66. Einarsen, S.; Raknes, B.I. Harassment at work and victimization of men. Violence Vict. 1997, 12, $247-263$. [CrossRef] [PubMed]

67. Namie, G. Workplace bullying: Escalated incivility. Ivey Bus. J. 2003, 68, 6.

68. Namie, G.; Namie, R. The Bully at Work: What You Can Do to Stop the Hurt and Reclaim Your Dignity on the Job; Sourcebooks: Naperville, IL, USA, 2009.

69. Baron, R.M.; Kenny, D.A. The moderator-mediator variable distinction in social psychological research: Conceptual, strategic, and statistical considerations. J. Pers. Soc. Psychol. 1986, 51, 1173-1182. [CrossRef]

70. Zhao, X.; Lynch, J.G.; Chen, Q. Reconsidering Baron and Kenny: Myths and Truths about Mediation Analysis. J. Consum. Res. 2010, 37, 197-206. [CrossRef]

71. Shah, A.; Hashmi, S.H.; Chishti, A. Much Has Changed since Baron and Kenny's (1986) Classic Paper: Let Us Learn What Kenny's (2012) Contemporary Mediation Analysis Prescribes (March 6, 2016). Jinnah Bus. Rev. 2012, 1, 58-67.

72. Day, A.L.; Livingstone, H.A. Chronic and acute stressors among military personnel: Do coping styles buffer their negative impact on health. J. Occup. Health Psychol. 2011, 6, 348-360. [CrossRef]

73. Hahn, S.E. The effect of locus of control on daily exposure, coping, and reactivity to work interpersonal stressors: A diary study. Personal. Individ. Differ. 2000, 29, 729-748. [CrossRef]

74. Dercon, S. Income Risk, Coping Strategies, and Safety Nets. World Bank Res. Obs. 2002, 17, 141-166. [CrossRef]

75. Smith, K.J.; Emerson, D.J.; Boster, C.R.; Everly, J.G.S. Resilience as a coping strategy for reducing auditor turnover intentions. Acc. Res. J. 2020, 33, 483-498. [CrossRef]

76. Clipa, O. Teacher Stress and Coping Strategies. In Proceedings of the 15th Edition of the International Conference on Sciences of Education, Studies and Current Trends in Science of Education, Suceava, Romania, 9-10 June 2018.

77. Baillien, E.; Neyens, I.; De Witte, H.; De Cuyper, N. A qualitative study on the development of workplace bullying: Towards a three way model. J. Community Appl. Soc. Psychol. 2009, 19, 16. [CrossRef]

78. Hollis, L.P. Lessons from Bandura's Bobo Doll Experiments: Leadership's Deliberate Indifference Exacerbates Workplace Bullying in Higher Education. J. Study Postsecond. Tert. Educ. 2019, 4, 85-102. [CrossRef]

79. Brande, W.V.D.; Baillien, E.; Elst, T.V.; De Witte, H.; Broeck, A.V.D.; Godderis, L. Exposure to Workplace Bullying: The Role of Coping Strategies in Dealing with Work Stressors. BioMed Res. Int. 2017, 2017, 1019529. [CrossRef]

80. Machackova, H.; Cerna, A.; Sevcikova, A.; Dedkova, L.; Daneback, K. Effectiveness of coping strategies for victims of cyberbullying. Cyberpsychol. J. Psychosoc. Res. Cyberspace 2013, 7, 5. [CrossRef]

Publisher's Note: MDPI stays neutral with regard to jurisdictional claims in published maps and institutional affiliations.

(C) 2020 by the authors. Licensee MDPI, Basel, Switzerland. This article is an open access article distributed under the terms and conditions of the Creative Commons Attribution (CC BY) license (http://creativecommons.org/licenses/by/4.0/). 